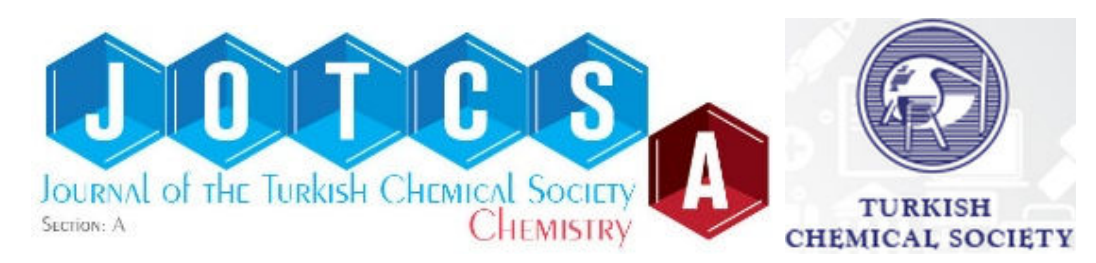

\title{
An Efficient Catalyst for Aldol Condensation Reactions
}

\author{
Yusuf HASSAN ${ }^{1 *}$ Rosa KLEIN ${ }^{2}$ Perry T. KAYE² \\ ${ }^{1}$ Department of Chemistry, Umaru Musa Yar'adua University, Katsina, Nigeria \\ ${ }^{2}$ Department of Chemistry, Rhodes University, Grahamstown, South Africa
}

\begin{abstract}
A new manganese complex was synthesised around $S, S-1,2-$ diaminocyclohexane linked ketopinic acid scaffold, and successfully utilised as a catalyst in the aldol condensation reactions of benzaldehyde with various aliphatic ketones to obtain products with excellent yield of $>99 \%$.
\end{abstract}

Keywords: Lewis acid; ketopinic acid; catalysis; aldol condensation.

Cite this: Hassan $Y$, Klein R, Kaye P. An Efficient Catalyst for Aldol Condensation Reactions. JOTCSA. 2017;4(2):41-48.

Submitted: February 22, 2017.Revised: March 10, 2017. Accepted: March 24, 2017.

DOI: $10.18596 /$ jotcsa. 293058 .

*Corresponding author. E-mail: yusuf.hassan@umyu.edu.ng 


\section{INTRODUCTION}

Aldol condensation reaction as a $\mathrm{C}-\mathrm{C}$ bond formation reaction continued to provide opportunity for the synthesis of valuable intermediates, natural products, as well as other biologically important compounds (1-3). The major concern with some of the reported methodologies has always been the issue of atom economy $(4,5)$. Although a number of catalytic methods were developed to improve the condition, it however often incorporates the use of harsh temperatures. For instance, Climent and co-workers have utilised solid base catalysts derived from hydrotalcites to achieve high yields and selectivities in the preparation of chalcones and flavanones of pharmacological interest, such as Vesidryl (6). Similarly Kottapali et al. have investigated the aldol condensation of benzaldehyde and acetone in the liquid phase on hydrotalcites tranformed into basic solid with good yield (7). Corma and Martin-Aranda have modified sepiolites by substituting a part of the $\mathrm{Mg} \mathrm{z+}$ located at the borders of its channels with alkaline ions to afford strong base catalyst for the aldol condensation (8). Also Corma et al. have carried out the condensation of benzaldehyde with various active methylene compounds in the presence of zeolites as a basic catalyst (9). In an effort to improve the catalytic activity of their earlier reported method on the use of hydrotalcites, Climent and co-workers successfully increased the surface area of the catalyst by sonication, and employed it in the aldol condensation reactions (10). In this work, a new organic-metal complex based on ketopinic acid scaffold and manganese was constructed and tested as catalyst in the aldol condensation of various aliphatic substrates at a mild temperature.

\section{MATERIALS AND METHODS}

Reagent-grade ethanol was used as received from commercial source, tetrahydrofuran was distilled from benzophenone/ketyl solutions and chloroform was passed through a column of basic alumina. Analytical thin-layer chromatography was performed on ALUGRAM XTRA silica gel $0.2 \mathrm{~mm}$ (containing a fluorescent indicator at $254 \mathrm{~nm}$ ). Flash chromatography was carried out on MN Kieselgel 60 0.063-0.2 mm/ 70-230 mesh. All other reagents were purchased from Aldrich and used as received. NMR spectra were recorded on Bruker Avance III HD spectrometer (400 and $600 \mathrm{MHz}$ ). All signals were expressed as ppm down field from TMS, referenced to the residual protonated solvent signals in ${ }^{1} \mathrm{H}$ NMR (7.26 ppm) and to the deuterated carbon signals in ${ }^{13} \mathrm{C}$ NMR $(77.36$ ppm). FTIR spectral measurements were carried out on a Perkin Elmer spectrum 400 FTIR spectrometer (ATR). Elemental analyses were conducted using an Elementar Vario 
micro cube. Melting points were determined by means of a Reichert apparatus and are uncorrected.

\section{2,2'-(1S,2S)-cyclohexane-1,2-diylbis(azan-1-yl-1-ylidene)bis(7,7-}

\section{dimethylbicyclo[2.2.1] heptane-1-carboxylic acid) $\mathbf{3}$}

Ketopinic acid (382 mg, $2.096 \mathrm{mmol}$ ) was dissolved in $\mathrm{CHCl}_{3}(5 \mathrm{~mL})$ and $\mathrm{S}, \mathrm{S}-1,2-$ diaminocyclohexane $(126 \mu \mathrm{L}, 1.05 \mathrm{mmol})$ acetic acid $(0.1 \mathrm{~mL})$ were added successively at room temperature. The mixture was refluxed for $36 \mathrm{~h}$ and then the reaction was quenched with $\mathrm{H}_{2} \mathrm{O}(5 \mathrm{~mL})$. The biphasic solution was extracted with $\mathrm{CH}_{2} \mathrm{Cl}_{2}(10 \mathrm{~mL})$, and then separated. The subsequent organic layer was washed with brine $(5 \mathrm{~mL})$, dried over anhydrous $\mathrm{MgSO}_{4}$, and concentrated. Purification of the crude product was effected by column chromatography on silica gel using $4 / 1 \mathrm{EtOAc} / \mathrm{CH}_{2} \mathrm{Cl}_{2}$ as eluent and the product were obtained as a white solid $(0.35 \mathrm{~g}, 29 \%) ;$ m.p. $161-164{ }^{\circ} \mathrm{C} ; \delta \mathrm{H}\left(400 \mathrm{MHz} \mathrm{CDCl}_{3}\right)$ $0.86(\mathrm{~s}, 6 \mathrm{H}), 1.22(\mathrm{~s}, 6 \mathrm{H}), 1.24-1.60(\mathrm{~m}, 6 \mathrm{H}), 1.67-1.81(\mathrm{~m}, 4 \mathrm{H}), 1.98-2.11(\mathrm{~m}, 6 \mathrm{H})$, $2.36(\mathrm{~m}, 2 \mathrm{H}), 2.52(\mathrm{~m}, 2 \mathrm{H}), 3.45(\mathrm{~m}, 2 \mathrm{H}) ; \delta \mathrm{c}\left(100 \mathrm{MHz} ; \mathrm{CDCl}_{3}\right) 20.2,20.5,27.2,28.2$, $31.7,32.7,35.3,43.8,50.0,60.8,64.7,173.3,183.6$ FTIR (neat, $\mathrm{cm}^{1}$ ) 2988, 2543, 1726,1580

\section{2,2'-(1S,2S)-cyclohexane-1,2-diylbis(azan-1-yl-1-ylidene)bis(7,7-} dimethylbicyclo[2.2.1] heptane-1-carboxylato) manganese (III) chloride 4

Solutions of ligand $3(119 \mathrm{mg}, 0.268 \mathrm{mmol})$ and $\mathrm{KOH}(0.5 \mathrm{M}, 8 \mathrm{~mL})$ in ethanol were allowed to reflux with $\mathrm{Mn}(\mathrm{OAc})_{2} \cdot 4 \mathrm{H}_{2} \mathrm{O}$ (138 mg, $0.563 \mathrm{mmol}$ ) under nitrogen atmosphere for $12 \mathrm{~h}$. The reaction mixture was then cooled to room temperature and then brine $(8 \mathrm{~mL})$ was added to give a biphasic solution which was later filtered and concentrated in vacuo. The residue obtained was redissolved in dichloromethane and the aqueous layer was removed using a separating funnel. After concentrating the organic layer, the resulting complex was recrystallized from acetonitrile to furnish a brown amorphous powder (66.8 mg, 47\% yield). Anal. Calcd for $\mathrm{C}_{26} \mathrm{H}_{36} \mathrm{ClMnN}_{2} \mathrm{O}_{4} \%$ : C, 60.75; $\mathrm{H}, 8.50 ; \mathrm{N}, 4.72$. Found: $\mathrm{C}, 60.75 ; \mathrm{H}, 8.52 ; \mathrm{N}, 4.73$. FTIR (neat, $\left.\mathrm{cm}^{-1}\right): 1738(\mathrm{C}=\mathrm{O})$, $1687(\mathrm{C}=\mathrm{N})$.

\section{Typical procedure for the aldol condensation reactions}

Potassium hexamethyldisilazide (KHMDS, $43.2 \mu \mathrm{L}, 0.0216 \mathrm{mmol}, 0.5 \mathrm{M}$ in toluene) and a solution of water ( $48 \mu \mathrm{L}, 0.048 \mathrm{mmol}, 1 \mathrm{M}$ in THF) were vigorously stirred for $20 \mathrm{~min}$. This was followed with the addition of ketone $(15 \mathrm{mmol})$ and further stirring for additional $10 \mathrm{~min}$. To the resulting solution, catalyst $\mathbf{S , S - 4}(66 \mathrm{mg}, 10$ mole \%) and aldehyde $(1.5 \mathrm{mmol})$ in THF $(0.5 \mathrm{~mL})$ were added. The mixture was continuously stirred with regular monitoring by ${ }^{1} \mathrm{H}$ NMR. 


\section{(Z)-2-benzylidenecyclohexanone 7}

Yellow oil; >99\% yield, $\delta \mathrm{H}\left(600 \mathrm{MHz} ; \mathrm{CDCl}_{3}\right) 1.50\left(\mathrm{q}, \mathrm{J}=2.0 \mathrm{~Hz}, \mathrm{CH}_{2}\right), 1.55(\mathrm{q}, \mathrm{J}=2.3$ $\left.\mathrm{Hz}, \mathrm{CH}_{2}\right), 1.57\left(\mathrm{t}, \mathrm{J}=3.1 \mathrm{~Hz}, \mathrm{CH}_{2}\right), 1.63\left(\mathrm{t}, \mathrm{J}=3.1 \mathrm{~Hz}, \mathrm{CH}_{2}\right), 6.88(\mathrm{~s}, 2 \mathrm{H}), 7.32-7.33$ $(\mathrm{m}, 2 \mathrm{H}), 7.40(\mathrm{~s}, 1 \mathrm{H}), 7.61(\mathrm{~s}, 1 \mathrm{H}), \delta \mathrm{c}\left(100 \mathrm{MHz} ; \mathrm{CDCl}_{3}\right) 22.2,24.3,35.0,128.2,128.3$, 128.4, 133.1, 134.0, 139.5, 198.3. FTIR (neat, $\mathrm{cm}^{-1}$ ) 3038, 1671, 1638,1450.

\section{(E)-2-benzylidene-6-methylcyclohexanone 9a}

Yellow oil; >99\% yield; $\delta \mathrm{H}\left(600 \mathrm{MHz} \mathrm{CDCl}_{3}\right) 1.22\left(\mathrm{~d}, \mathrm{~J}=1.2 \mathrm{~Hz}, \mathrm{CH}_{3}\right), 1.23-1.24(\mathrm{~m}$, $2 \mathrm{H}), 1.32-1.36(\mathrm{~m}, 2 \mathrm{H}), 2.10-2.12(\mathrm{~m}, 2 \mathrm{H}), 2.22-2.32(\mathrm{~m}, 2 \mathrm{H}), 6.89(\mathrm{~s}, 2 \mathrm{H}), 7.41-7.43$ $(\mathrm{m}, 2 \mathrm{H}), 7.54(\mathrm{~s}, 1 \mathrm{H}), 7.81(\mathrm{~s}, 1 \mathrm{H}) . \delta \mathrm{c}\left(100 \mathrm{MHz} ; \mathrm{CDCl}_{3}\right)$ 16.2, 26.3, 29.2, 30.6, 40.6, 133.2, 136.3, 136.7, 134.2, 134.8, 140.1, 199.3. FTIR (neat, $\mathrm{cm}^{-1}$ ) 3045, 1674, 1632, 1447.

\section{(E)-2-benzylidene-4-methylcyclohexanone $\mathbf{9 b}$}

Yellow oil; >99\% yield, $\delta \mathrm{H}\left(600 \mathrm{MHz} ; \mathrm{CDCl}_{3}\right) 0.99\left(\mathrm{~d}, \mathrm{~J}=0.5 \mathrm{~Hz}, \mathrm{CH}_{3}\right), 1.62-1.68(\mathrm{~m}$, $2 \mathrm{H}), 1.85-1.93(\mathrm{~m}, 2 \mathrm{H}), 2.33-2.80(\mathrm{~m}, 2 \mathrm{H}), 2.86-2.93(\mathrm{~m}, 1 \mathrm{H}), 3.20-3.52(\mathrm{~m}, 1 \mathrm{H})$, 3.62-3.72 (m, 1H), $7.02(\mathrm{~s}, \mathrm{CH}), 7.61-7.68(\mathrm{~m}, 2 \mathrm{H}), 7.72(\mathrm{~s}, 1 \mathrm{H}), 7.84(\mathrm{~s}, 1 \mathrm{H}) . \delta \mathrm{c}(100$ $\left.\mathrm{MHz}_{2} \mathrm{CDCl}_{3}\right) 16.2,26.3,29.2,30.6,40.3,133.2,136.3,136.7,134.2,134.8,140.1$, 199.5. FTIR (neat, $\mathrm{cm}^{-1}$ ) 3044, 1675, 1632, 1447.

\section{Trans-1-phenylhept-1-en-3-one 9c}

Yellow oil; >99\% yield, $\delta \mathrm{H}\left(600 \mathrm{MHz} ; \mathrm{CDCl}_{3}\right) 0.96(\mathrm{t}, J=0.9 \mathrm{~Hz}, 3 \mathrm{H}), 1.52-1.59(\mathrm{~m}, 4 \mathrm{H})$, $3.20(\mathrm{t}, J=3.1 \mathrm{~Hz}, 2 \mathrm{H}), 6.53(\mathrm{~d}, J=12.0 \mathrm{~Hz}, 1 \mathrm{H}), 6.66(\mathrm{~d}, J=12.0 \mathrm{~Hz}, 1 \mathrm{H}), 6.83(\mathrm{~d}, J$ $=6.5,2 \mathrm{H}), 7.66-7.68(\mathrm{~m}, 3 \mathrm{H}) . \delta \mathrm{c}\left(100 \mathrm{MHz} \mathrm{CDCl}_{3}\right)$ 12.3, 23.4, 28.6, 40.2, 128.3, 129.0, 131.1, 135.1, 140.1, 147.2, 199.5. FTIR (neat, $\mathrm{cm}^{-1}$ ) 3051, 1668, 1646, 1510.

\section{Cis-4,4-dimethyl-1-phenylpent-1-en-3-one 9d}

Yellow oil ; >99\% yield, $\delta \mathrm{H}\left(600 \mathrm{MHz} ; \mathrm{CDCl}_{3}\right) 1.51(\mathrm{~s}, 9 \mathrm{H}), 6.93(\mathrm{~d}, \mathrm{~J}=6.0 \mathrm{~Hz}, 1 \mathrm{H}), 7.43$ $(\mathrm{d}, J=6.0 \mathrm{~Hz}, 1 \mathrm{H}), 7.66-7.68(\mathrm{~m}, 2 \mathrm{H}), 7.72-7.75(\mathrm{~m}, 3 \mathrm{H}) . \delta \mathrm{c}\left(100 \mathrm{MHz} ; \mathrm{CDCl}_{3}\right) 33.2$, $43.1,127.3,129.1,129.8,133.10,138.0,140.2,198.5$. FTIR (neat, $\mathrm{cm}^{-1}$ ) 3055, 1671, 1644,1525 .

\section{RESULTS AND DISCUSSION}

The ligand 3 reported by Yang et al. (11) was synthesised using the standard procedure, followed by the complexation step (Scheme 1) to obtain the new $\mathrm{Mn}$ (III) complex $\mathbf{S}, \mathbf{S}-\mathbf{4}$ 
(12). Hence, the synthesis was carried out by refluxing ketopinic acid $\mathbf{1}$ with the $S, S-1,2-$ diaminocyclohexane $\mathbf{2}$ and a catalytic amount of glacial acetic acid, using chloroform as solvent (Scheme 1). Condensation of ketopinic acid (2 equiv.), with the $S, S-1,2-$ diaminocyclohexane as a linker enabled the generation of the C-2 symmetry and expand the space occupied by the ligand on each face of the final complex. It was hoped that the position of the manganese atom tightly situated at the centre of the ketopinic acid moieties would enhance the coordination of the electrophilic centres of the substrates during reaction.

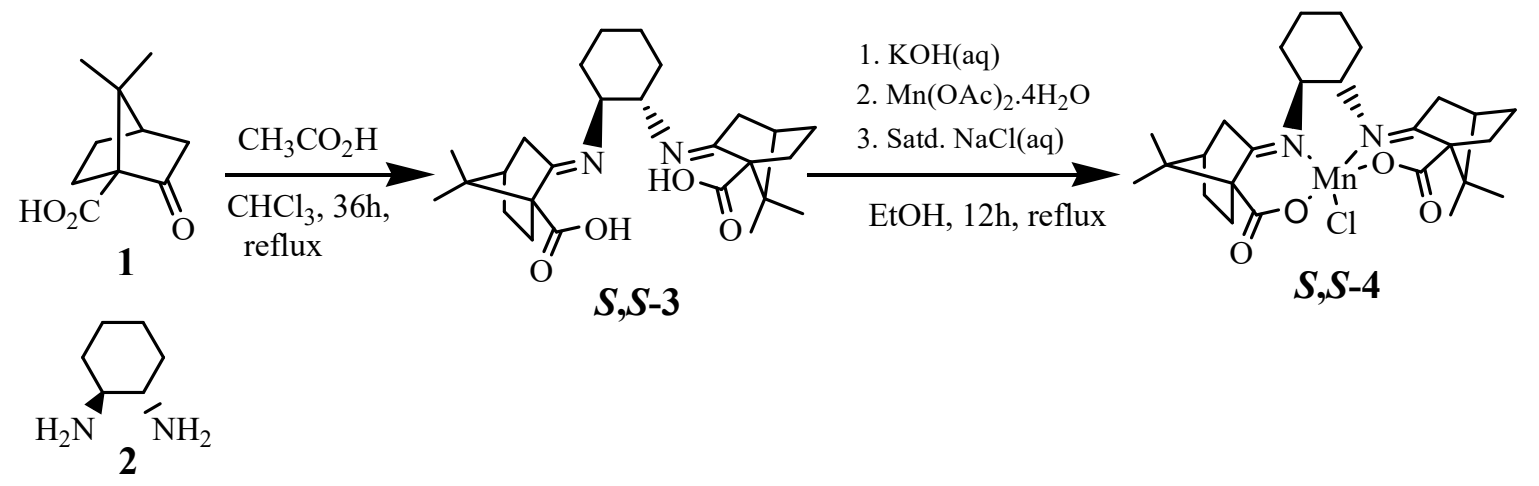

Scheme 1. Synthesis of ketopinic acid-derived complex

The catalytic acitivity of complex $\mathbf{S , S - 4}$ was investigated following the procedure reported by Yoshikawa et al. (13) with modification. Hence benzaldehyde was reacted with cyclohexanone in different ethereal solvents and at three catalyst loadings (Table 1 ). The results shows that THF is the most efficient solvent as it allows the formation of the aldol product in $>99 \%$ yield at relatively shorter time. Attempt to reduce the catalyst loading result in longer duration of the reaction. Although not captured in Table 1, but the method development reveals that any attempt to reduce the cyclohexanone equivalent furnish the corresponding aldol in negligible amount. In fact it could only be detected in the ${ }^{1} \mathrm{H}$ NMR spectroscopic analysis of the crude mixture. 
Table 1. Aldol condensation of benzaldehyde with cyclohexanone in three different solvents in the presence of complex $\mathbf{S}, \mathbf{S}-\mathbf{4}^{1}$<smiles>O=C(O)C1CCCCC1=O</smiles>

5

6 7

\begin{tabular}{cccc}
\hline Solvent & $\mathbf{4}(\mathbf{m o l e} \%)$ & Time $\mathbf{~} \mathbf{h})$ & Yield $\left.^{(\%)}\right)^{2}$ \\
\hline \multirow{2}{*}{ THF } & 1 & 18 & $>99$ \\
& 5 & 15 & $>99$ \\
& 10 & 4.5 & $>99$ \\
\hline \multirow{2}{*}{ EtOAC } & 1 & 24 & $>99$ \\
& 5 & 21 & $>99$ \\
& 10 & 24 & $>99$ \\
\hline \multirow{2}{*}{ Dioxane } & 1 & 24 & trace \\
& 5 & 21 & trace \\
& 10 & 24 & trace \\
\hline
\end{tabular}

${ }^{1}$ Benzaldehyde $(1.5 \mathrm{mmol})$, cyclohexanone (15 mmol).Cis assignment for 7 was determined using DFT calculation of the lowest energy isomer.

${ }^{2}$ Determined by the analysis of the reaction mixture using ${ }^{1} \mathrm{H}$ NMR spectroscopy

Based on the catalyst performance, other substrates were explored to further ascertain its efficacy. The results (Table 2 ) demonstrate that the catalyst has relatively wide spectrum of activity.

Table 2. Aldol condensation of various aliphatic substrates in the presence of $\mathbf{S , S - 4}$ (10 mole $\%)^{1}$

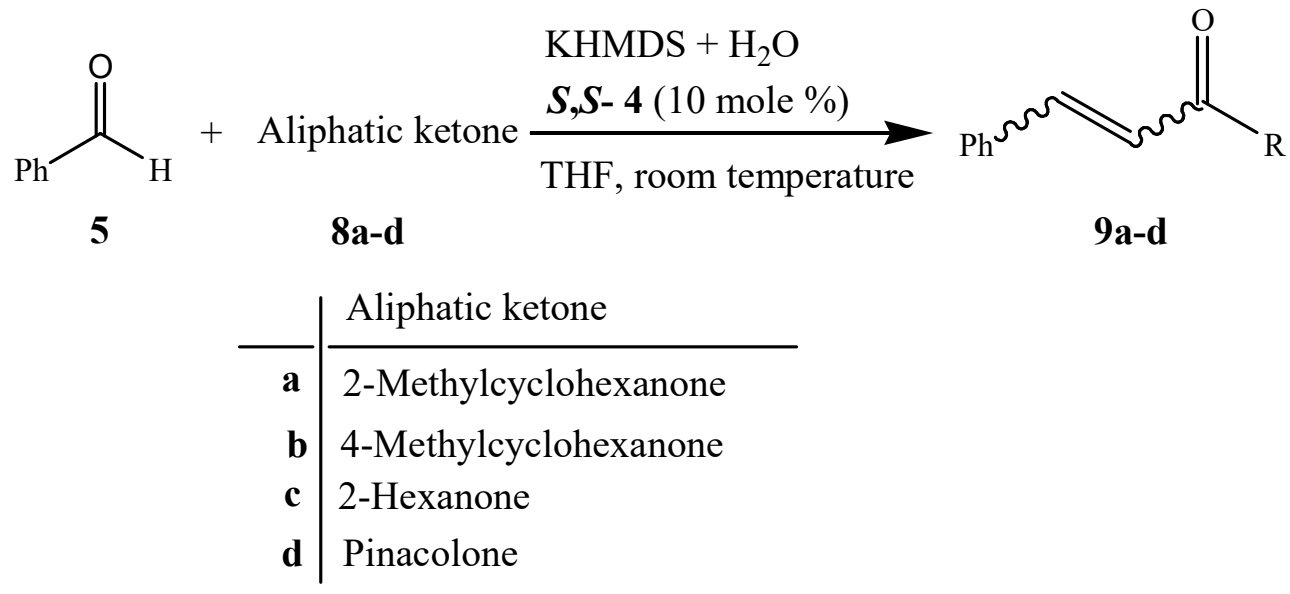




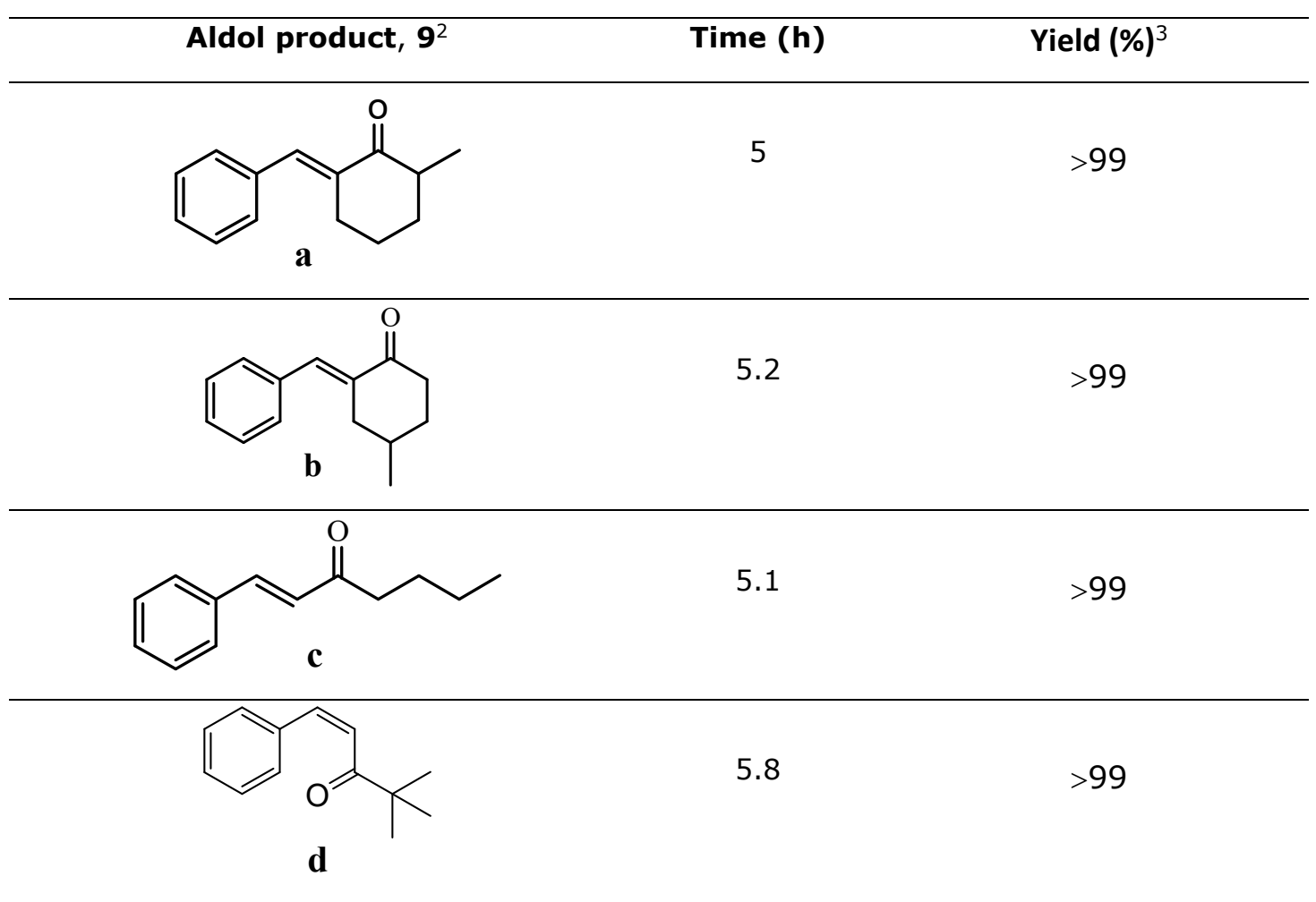

${ }^{1}$ Benzaldehyde $(1.5 \mathrm{mmol})$, Ketone $(15 \mathrm{mmol})$

${ }^{2}$ Geometrical assignment was determined using DFT calculation of the lowest energy isomers

${ }^{3}$ Determined by the analysis of the reaction mixture using ${ }^{1} \mathrm{H}$ NMR spectroscopy

\section{CONCLUSIONS}

Ketopinic acid was successfully employed as a scaffold in the synthesis of a manganese (III) complex. The catalytic efficiency of the obtained complex was investigated in the aldol condensation of benzadehyde with cyclohexanone to obtain product with excellent yield at a short duration. Subsequently other aliphatic ketones were reacted with the benzaldehyde at the optimized reaction condition to furnish the corresponding aldol products with an impressive yield. Interestingly, it was found that irrespective of the structure of the aliphatic ketone, the yield of the products was always excellent within a short duration. This suggest that the catalytic system developed in this work possess strong Lewis acidity which help in the activation of the carbonyl groups in the reacting species. 


\section{ACKNOWLEDGMENTS}

The financial support of the National Research Foundation and the Tertiary Education Trust Fund, Nigeria for granting fellowship to Yusuf Hassan is gratefully acknowledged.

\section{REFERENCES}

1. Heathcock CH, Ellis JE, McMurry JE, Coppolino A. Acid-catalyzed Robinson Annelations. Tetrahedron Letters. January 1971;12(52):4995-6.

2. Vashchenko V, Kutulya L, Krivoshey A. Simple and Effective Protocol for Claisen-Schmidt Condensation of Hindered Cyclic Ketones with Aromatic Aldehydes. ChemInform [Internet]. November 20, 2007 [source 03 April 2017];38(47). Available at: http://doi.wiley.com/10.1002/chin.200747094

3. Badía C, Castro JM, Linares-Palomino PJ, Salido S, Altarejos J, Nogueras M, vd. (E)-6-(2,2,3Trimethyl-cyclopent-3-enyl)-hex-4-en-3-one. Molbank. March 29, 2004;2004(1):M388.

4. Sugiura $M$, Ashikari $Y$, Nakajima M. One-Pot Synthesis of $\beta, \beta$-Disubstituted $a, \beta$-Unsaturated Carbonyl Compounds. The Journal of Organic Chemistry. September 04, 2015;80(17):8830-5.

5. Wang Z, Yin G, Qin J, Gao M, Cao L, Wu A. An Efficient Method for the Selective Iodination of a, $\beta$-Unsaturated Ketones. Synthesis. November 2008;2008(22):3675-81.

6. Climent MJ, Corma A, Iborra S, Primo J. Base Catalysis for Fine Chemicals Production: ClaisenSchmidt Condensation on Zeolites and Hydrotalcites for the Production of Chalcones and Flavanones of Pharmaceutical Interest. Journal of Catalysis. January 1995;151(1):60-6.

7. Rao KK, Gravelle M, Valente JS, Figueras F. Activation of Mg-Al Hydrotalcite Catalysts for Aldol Condensation Reactions. Journal of Catalysis. January 1998;173(1):115-21.

8. Corma A. Alkaline-substituted sepiolites as a new type of strong base catalyst. Journal of Catalysis. July $1991 ; 130(1): 130-7$.

9. Corma A, Fornés V, Martín-Aranda RM, García H, Primo J. Zeolites as base catalysts: Condensation of aldehydes with derivatives of malonic esters. Applied Catalysis. March $1990 ; 59(1): 237-48$.

10. Climent M. Increasing the basicity and catalytic activity of hydrotalcites by different synthesis procedures. Journal of Catalysis. July 2004;225(2):316-26.

11. Yang K-S, Lee W-D, Pan J-F, Chen K. Chiral Lewis Acid-Catalyzed Asymmetric Baylis-Hillman Reactions. The Journal of Organic Chemistry. February 2003;68(3):915-9.

12. Kureshy RI, Khan NH, Abdi SHR, Iyer P, Bhatt AK. Enantioselective catalytic epoxidation of nonfunctionalized prochiral olefins by dissymmetric chiral Schiff base complexes of Mn(III) and Ru(III) metal ions II. Journal of Molecular Catalysis A: Chemical. June 1997;120(1-3):101-8.

13. Yoshikawa N, Yamada YMA, Das J, Sasai H, Shibasaki M. Direct Catalytic Asymmetric Aldol Reaction. Journal of the American Chemical Society. May 1999;121(17):4168-78. 